Article

\title{
Aeroelastic Analysis of a Coplanar Twin-Rotor Wind Turbine
}

\author{
Amr Ismaiel 1,2,*(D) and Shigeo Yoshida ${ }^{3} \mathbb{D}$ \\ 1 Interdisciplinary Graduate School of Engineering Sciences, Kyushu University, 6-1 Kasugakoen, Kasuga, \\ Fukuoka 816-8580, Japan \\ 2 Faculty of Engineering and Technology, Future University in Egypt (FUE), 5th Settlement, \\ New Cairo 11835, Egypt \\ 3 Research Institute for Applied Mechanics, Kyushu University, 6-1 Kasugakoen, Kasuga, Fukuoka 816-8580, \\ Japan; yoshidas@riam.kyushu-u.ac.jp \\ * Correspondence: amr.mohamed@fue.edu.eg or amrmetwally@riam.kyushu-u.ac.jp; Tel.: +81-80-5978-3397
}

Received: 29 March 2019; Accepted: 14 May 2019; Published: 17 May 2019

\begin{abstract}
Multi-rotor system (MRS) wind turbines can be a competitive alternative to large-scale wind turbines. In order to address the structural behavior of the turbine tower, an in-house aeroelastic tool has been developed to study the dynamic responses of a 2xNREL 5MW twin-rotor configuration wind turbine. The developed tool has been verified by comparing the results of a single-rotor configuration to a FAST analysis for the same simulation conditions. Steady flow and turbulent load cases were investigated for the twin-rotor configuration. Results of the simulations have shown that elasticity of the tower should be considered for studying tower dynamic responses. The tower loads, and deformations are not straightforward with the number of rotors added. For an equivalent tower, an additional rotor will increase the tower-top deflection, and the tower-base bending moment both in the fore-aft direction will be more than doubled. The tower torsional stiffness becomes a crucial factor in the case of a twin-rotor tower to avoid a severe torsional deflection. Tower natural frequencies are dominant over the flow conditions in regards to the loads and deflections.
\end{abstract}

Keywords: aeroelasticity; multi-rotor system; wind turbine

\section{Introduction}

With the world's high demand of energy, and the limitation of the amount of fossil fuels, renewable energies have become a field of interest for many researchers. Wind energy is one of the most growing renewable sources of energy, in terms of usage and research topics. The global cumulative installed wind capacity has increased 2200\% from the year 2001 to 2017 [1]. At present, horizontal axis wind turbines remain the dominant wind energy conversion technology. In the past decades, the trend was to increase the diameter of the rotor, since the power produced is proportional to the rotor area. Currently, the world's largest wind turbine has a 12 MW capacity, and a 107-meter blade length [2]. However, with this large size comes big challenges, such as the huge transportation and installation cost of extremely large wind turbines and the severe structure dynamic loads on the blades and the tower, as well as the need to develop each component, including the blade, bearing, generator, gearbox, etc. to be suitable for the large-scale single rotor turbines, which includes risk in cost and quality. Also, it includes a risk if a failure occurs; then the whole wind turbine will shut down and no power will be produced until the failed part is fixed or replaced [3].

The multi-rotor systems (MRS) is a technology with a long history that goes back to 1930, but it has fallen out of consideration for its structure complexity, while large scale single rotor wind turbines have become technically feasible [4]. However, with current advanced materials technology, the materials 
used to construct the rotors have a higher strength to weight ratio. With those advances in the materials technology, MRS is a promising alternative to large-scale wind turbines. The main advantages of MRS are the standardization of the wind turbine components, ease of transportation (since the rotors are of a small scale compared to large-scaled wind turbines), ease of installation, and the cost and the reliability of wind turbines, since multi rotors ensure that if there is a failure in one rotor, then the other rotors will still produce power. The major challenges in an MRS are the complexity of the supporting structure, the yawing system, and the aerodynamic interaction between rotors placed closely to each other.

As MRS has become an interesting field of research, researchers from many countries have made attempts to issue very interesting research points. Some attempts were interested in studying aerodynamics and the aerodynamic interaction between the rotors of an MRS. Experiments made by Goltenbott et al. [5] have shown that two and three diffuser augmented rotor configurations can increase the power produced per rotor by $5 \%$ and $9 \%$ respectively, compared to a single rotor. Also, the computational fluid dynamic (CFD) simulations made by Chasapogiannis et al. [6] on a seven rotor system have shown a power increase of 3\% per rotor. The coherence effect on the produced power and tower loads on a seven rotor MRS has been studied by Yoshida et al. [7]; Wind models with three different coherences were used in the simulation and showed that larger coherence implies higher power production yet increases the collective loads. MRS was also found to improve the wake recovery; the wakes were found to recover faster for MRS compared to a single-rotor configuration and showed a smaller turbulence intensity in the wake [8].

One of the leading research institutes showing great interest in MRS is the Technical University of Denmark (DTU). The DTU constructed a four rotor wind turbine at the Risø campus. They conducted experiments as well as simulations for the four rotor wind turbine, and both agreed that the interaction between the rotors improved the power performance by $1.8 \pm 0.2 \%$, which can increase the annual power production by $1.5 \pm 0.2 \%$ [9].

Downscaling the design and cost of wind turbine rotors to replace a single large rotor with multiple smaller rotors has been done by Verma et al. [10]. A $5 \times 1 \mathrm{MW}$ multi-rotor turbine was compared to the National Renewable Energy Laboratory (NREL) 5MW single rotor turbine. The scaled down multi-rotor configuration has shown a $37 \%$ reduction in weight and a $25 \%$ reduction in cost compared to a single rotor producing the same amount of power. As an extension of Verma's work, Mate et al. [11] have designed a support structure for the five rotor configuration proposed in their colleague's work, in addition to other configurations that Mate proposed himself. A finite element approach was used for modeling the support structure. However, these simulations did not include a study of the aeroelastic behavior of either the blades or the support structure and the wind conditions.

Aeroelastic analyses for wind turbines are doable for single rotors using either a Computaional Fluid Dynamics (CFD) model like the Fluid Structure Interaction (FSI) made by Bazilevs et al. [12] or Halawa et al. [13] or using deterministic models. NREL's tool, FAST, is one of the most used aeroelastic tools for modeling wind turbines, it is based on models derived from fundamental theory of aerodynamics and structure analysis, which are more time-efficient compared to CFD models [14].

So far there has been no research or open-source tools proposed that introduce aeroelastic analysis for the multi-rotor concept. In this work, the support structure of an MRS is being aero-elastically analyzed, so that structural problems can be addressed in further research studies. It is the first attempt to develop an in-house aeroelastic tool for an MRS support structure. In this work, the present tool is used to model a twin-rotor wind turbine, with two coplanar rotors placed on a T-shaped tower. This tool can be later extended to model support structures for different configurations of MRS.

The theory used in this work is the Blade Element Momentum (BEM) theory, which is used to calculate the aerodynamic loads, and the virtual work method with a modal approach to calculate the structural deformations of blades and tower. Combining the two theories creates an aeroelastic interface between the blades and tower on one hand, and wind on the other. 
The results of the present tool are verified by comparing results of a single rotor wind turbine, to NREL's FAST results of the same turbine model. Then, the results for the twin-rotor configuration are introduced.

\section{Mathematical Model}

\subsection{Aerodynamic Model}

Unsteady BEM was used in this work to estimate the aerodynamic loads tangential to and normal on each section along the blade. The blade coordinate system was used for the governing equations, as shown in Figure 1.

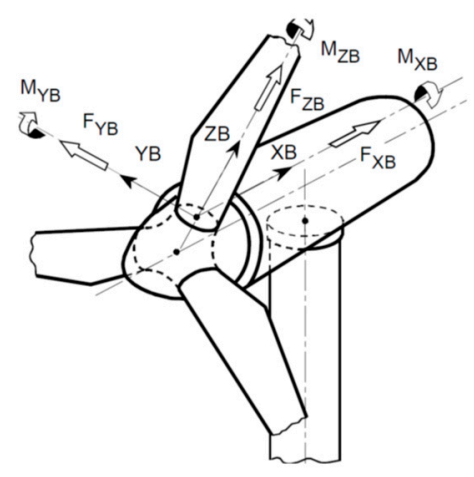

Figure 1. Blade Coordinate System [15].

Initially, the relative wind velocity components on each blade section, in the rotor plane, tangential to the blade width ( $y_{B}$-axis), and normal to it ( $x_{B}$-axis) as shown in Figure 2 are as follows:

$$
\begin{gathered}
V_{r e l, x_{B}}=V_{0, x_{B}}+w_{x_{B}} \\
V_{r e l, y_{B}}=V_{0, y_{B}}-\omega r+w_{y_{B}}
\end{gathered}
$$

where $V_{0}$ is the inflow velocity, $\omega$ is the rotational speed of the rotor, $r$ is the blade section position, and $w_{x B}, w_{y B}$ are the induced velocities in $x_{B}$ and $y_{B}$ directions.

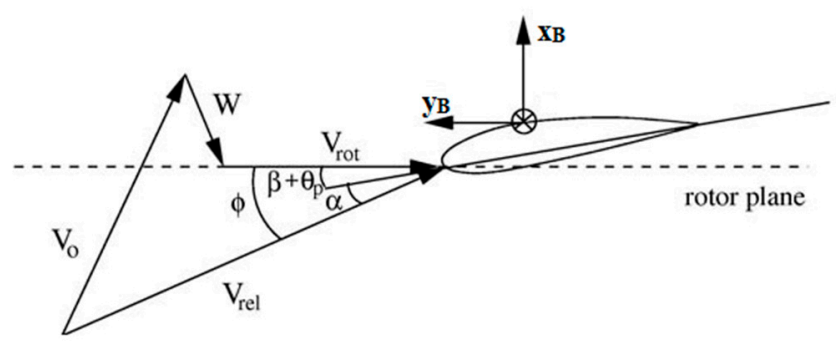

Figure 2. Velocity Triangle on a Blade Section [16].

Prandtl's tip loss factor and Glauert correction are used in the calculation of induced velocities; then, depending on the relative velocity components on each blade section, for every time step, the coefficients of lift and drag forces can be interpolated from the blade airfoils' data tables. Next, lift and drag forces can be calculated for each section, and hence the aerodynamic loads in the plane of rotation $\left(L_{y B, \text { aero }}\right)$ and normal to it $\left(L_{x B, \text { aero }}\right)$ can also be calculated. Dynamic wake, dynamic stall, and yaw misalignment effects were ignored in this study. With the tangential and normal load distributions known, the rotor aerodynamic thrust, torque, and power can be calculated [16]. 


\subsection{Structure Model}

The principle of virtual work was used to calculate the structure dynamics parameters. This principle is a method that helps to set up the correct matrices for a discretized mechanical system, such as Newton's second law shown in Equation (3). This method is well suited for a chained multi-body system like wind turbines:

$$
M \ddot{x}+C \dot{x}+K x=F_{g}
$$

where; $\boldsymbol{M}$ is the mass matrix, $C$ is the damping matrix, $\boldsymbol{K}$ is the stiffness matrix, and $\boldsymbol{F}_{g}$ is the generalized forces array. $x, \dot{x}$, and $\ddot{x}$, are the generalized coordinates for the three modes used in the model, their first, and second time derivatives, respectively.

The degrees of freedom used in this model are the uncoupled modal shapes for both the blades and the tower. For the blades, the first and second flap-wise, and the first edge-wise modes are used, denoted by $u^{f 1}, u^{f 2}$, and $u^{e 1}$ respectively. For the tower, the first and second fore-aft, and the first side-side modes are used, denoted by $u^{f a 1}, u^{f a 2}$, and $u^{s s 1}$. These modes were chosen because the orthogonality constraint between the eigen modes turns the mass matrix into a diagonal matrix, and hence into the damping and stiffness matrices that are dependent on the mass matrix. This results in uncoupled differential equations that can be solved by a fourth order Runge-Kutta numerical technique.

Solving this system of equations results in the values of $x, \dot{x}$, and $\ddot{x}$, on which the deformation of either the blade or the tower is assumed to be dependent, as a linear combination of the three modes. For instance, in the case of the blade, with a stiff tower, the deformation distribution along the blade section position $(r)$, denoted by $u_{x B}$ in the flap-wise direction and $u_{y B}$ in the edge-wise direction, will be as follows:

$$
\begin{aligned}
& u_{x B}(r)=x_{1} u_{x B}^{f 1}(r)+x_{2} u_{x B}^{e 1}(r)+x_{3} u_{x B}^{f 2}(r) \\
& u_{y B}(r)=x_{1} u_{y B}^{f 1}(r)+x_{2} u_{y B}^{e 1}(r)+x_{3} u_{y B}^{f 2}(r) .
\end{aligned}
$$

The velocity and acceleration distribution along the blade are calculated the same way, except for using $\dot{x}$, and $\ddot{x}$ instead of $x$ [17].

\subsection{Aeroelastic Coupling}

The deformation of the blade, together with the velocity and acceleration of its vibration, will result in change in the loads and hence structural deformation in the next time-step. The relative wind velocity components on the blade sections can now be updated to include the blade vibrations, with the blade velocity distribution always opposing the wind direction. Equations (1) and (2) can be updated as follows:

$$
\begin{gathered}
V_{r e l, x B}=V_{0, x B}+w_{x B}-\dot{u}_{x B} \\
V_{r e l, y B}=V_{0, y B}-\omega r+w_{y B}-\dot{u}_{y B}
\end{gathered}
$$

where $\dot{u}_{x B}$, and $\dot{u}_{y B}$ are the blade sections' vibrational velocities in the flap-wise and edge-wise directions.

The loads on the blade sections are also updated to include gravitational loads and inertia loads due to the blade vibrations. The total load distribution along the blade sections in the normal and tangential directions to the plane of rotation will be as follows:

$$
\begin{gathered}
L_{x B}(r)=L_{x B, \text { aero }}(r)-m^{\prime}(r) \ddot{u}_{x B}(r)+m^{\prime}(r) g \sin \left(\theta_{t}+\sin \theta_{c}\right) \cos \theta_{A} \\
L_{y B}(r)=L_{y B, \text { aero }}(r)-m^{\prime}(r) \ddot{u}_{y B}(r)+m^{\prime} \sin \theta_{A}
\end{gathered}
$$

where $m^{\prime}$ is the mass density distribution along the blade length, $\ddot{u}_{x B}$ and $\ddot{u}_{y B}$ are the blade sections' vibrational accelerations, $\theta_{t}$ is the tilt angle, $\theta_{c}$ is the cone angle, and $\theta_{A}$ is the azimuth angle. The loads in the direction of the blade length are neglected. 
The updated relative wind velocity and loads are used for the next time step, guaranteeing that both the aerodynamics and structure models affect each other to create an aeroelastic model.

The tower is modelled independently from the blades, and the rotor loads are transmitted to the tower, including rotor thrust, weight, and torque, taking into consideration the aeroelastic behaviour of those loads. Also, the aerodynamic load on the tower itself is calculated, considering the tower vibrations in the relative wind speed to the tower, and the tower inertial loads.

\section{Verification of the Single Rotor Model}

The single rotor wind turbine simulated for validation is the NREL 5MW wind turbine. In order to ensure the reliability of the developed aeroelastic tool, the results of aerodynamic analysis, dynamic structural analysis, and aeroelastic analysis are compared to results of the NREL 5MW results in the definition report of the wind turbine [18] and FAST simulation for the aeroelastic case.

\subsection{Model Outline}

The geometric and material properties of the turbine blades and tower are fully defined in the NREL definition report. General rotor specifications are shown below:

- $\quad$ Rating: $5 \mathrm{MW}$.

- $\quad$ Rotor orientation, configuration: Upwind, 3 Blades.

- Rotor Diameter: $126 \mathrm{~m}$.

- Hub Height: $90 \mathrm{~m}$.

- Cut-in, Cut-out Wind Speed: $3 \mathrm{~m} / \mathrm{s}, 25 \mathrm{~m} / \mathrm{s}$.

- $\quad$ Rated Wind Speed: $11.4 \mathrm{~m} / \mathrm{s}$.

- Rotor Mass: $110,000 \mathrm{~kg}$.

- Nacelle Mass: $240,000 \mathrm{~kg}$.

- Tower Mass: 347,460 kg.

Figure 3 shows a CAD model for the turbine blade.

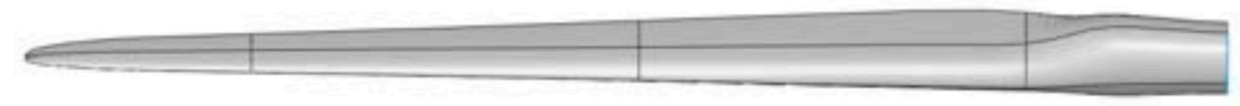

Figure 3. NREL 5MW wind turbine blade [19].

The blade and tower structural specifications are shown in Figure 4.

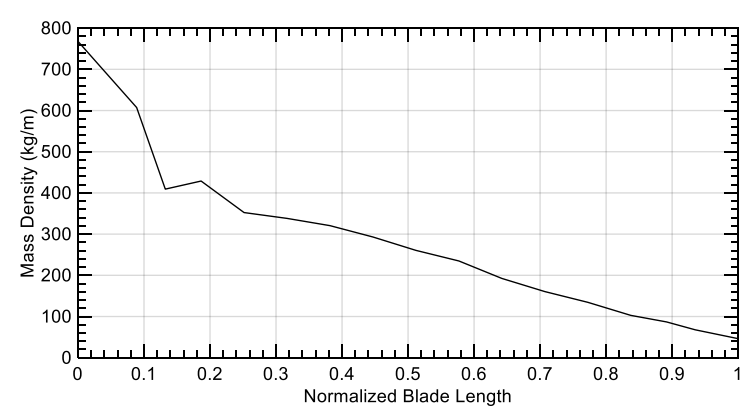

(a)

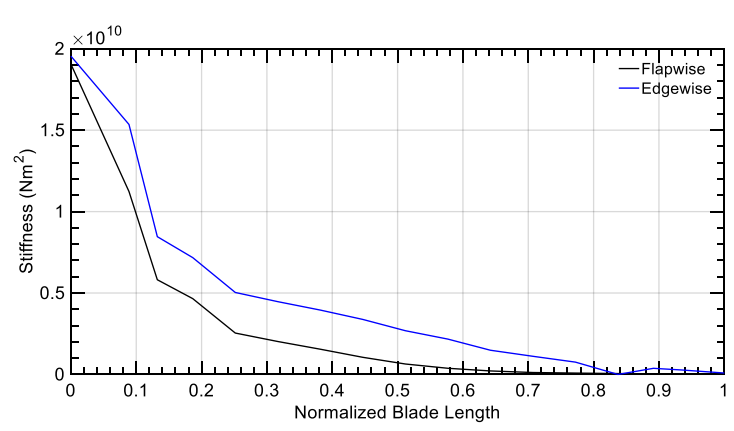

(b)

Figure 4. Cont. 


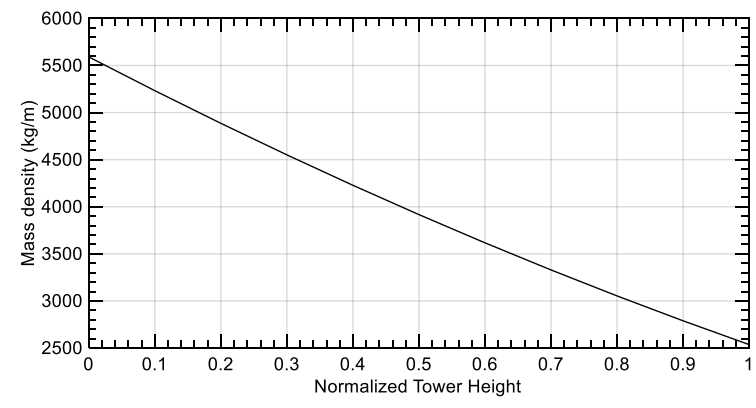

(c)

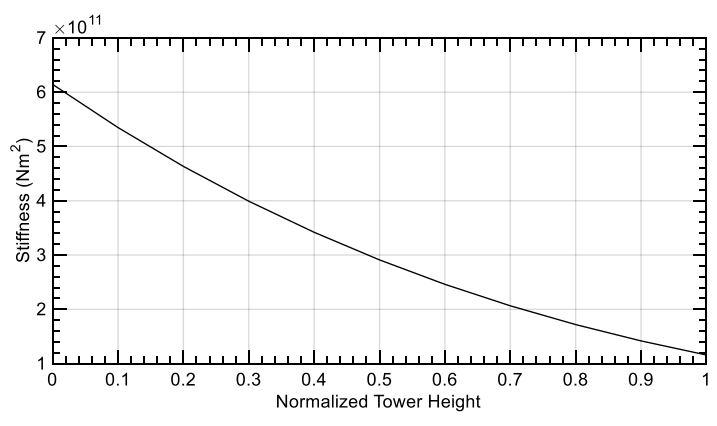

(d)

Figure 4. Blade structural properties: (a) Blade mass density distribution; (b) Blade stiffness distribution; (c) Tower mass density distribution; and (d) Tower stiffness distribution.

\subsection{Rotor Aerodynamics}

The NREL 5MW wind turbine is a pitch-controlled turbine. Over the rated wind speed of $11.4 \mathrm{~m} / \mathrm{s}$, the pitch control is applied to maintain the rated power output and rotor speed. So far, pitch control has not been applied in the present tool. Accordingly, the full power region cannot be simulated in the current version of the tool, but it will be added later. The BEM in the developed tool is run for wind speeds starting from the cut-in speed of $3 \mathrm{~m} / \mathrm{s}$, to the rated speed of $11.4 \mathrm{~m} / \mathrm{s}$. The rotor power, thrust, and torque are compared. The results are shown in Figure 5.

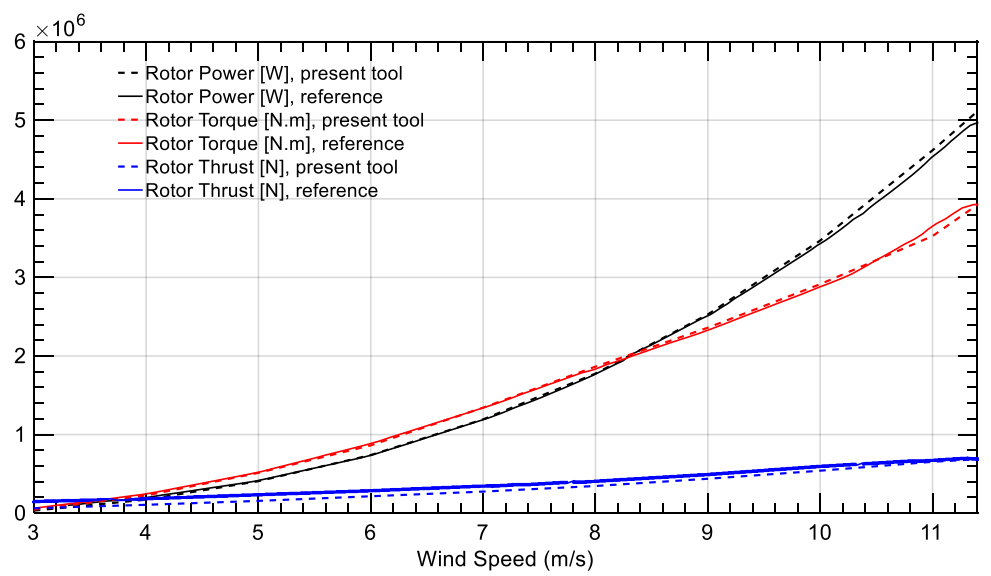

Figure 5. Steady state responses: comparison between results of the developed tool to NREL reference file.

Figure 5 shows good agreement between the calculated steady state values of the power, torque, and thrust of the developed tool, compared to the turbine definition document's results. This agreement proves that the first part of the tool concerned with calculating the aerodynamic responses, without considering the aeroelastic behavior of the blades, is reliable, and the next step would be the dynamic responses of the blades and tower.

\subsection{Modal Analysis}

In this section, the free vibration modes of the blades and tower are investigated. The structural model is based on the uncoupled modes of vibrations, and it is important that the mode shapes and natural frequencies will be correct, before proceeding to the aeroelastic coupling between the aerodynamics and structural behavior of both the blade and the tower.

The NREL tool Modes [20] was used to calculate the uncoupled mode shapes and natural frequencies of the blades and the tower. Mass and stiffnesses distribution along the blade and tower are 
available in the NREL 5MW definition document and were used as input for Modes. The mode shapes and natural frequencies are also available in the definition document and are shown for comparison with the results of simulation.

\subsubsection{Blades}

The mode shapes used in the structural model are the first and second flap-wise modes, and the first edge-wise mode. Natural frequencies and mode shape comparisons are shown in Table 1.

Table 1. Natural frequencies of the blade.

\begin{tabular}{cccc}
\hline Mode & Calculated (Hz) & Reference (Hz) & Deviation (\%) \\
\hline First flap-wise & 0.71 & 0.70 & 1.4 \\
Second flap-wise & 2.02 & 2.02 & 0.0 \\
First edge-wise & 1.08 & 1.08 & 0.0 \\
\hline
\end{tabular}

Results of the natural frequencies from the Modes simulation agree with the reference values In Figures 6 and 7, the mode shapes calculated by Modes are compared to the mode shapes in the NREL 5MW definition file. The results are almost identical for both the flap-wise and edge-wise modes.

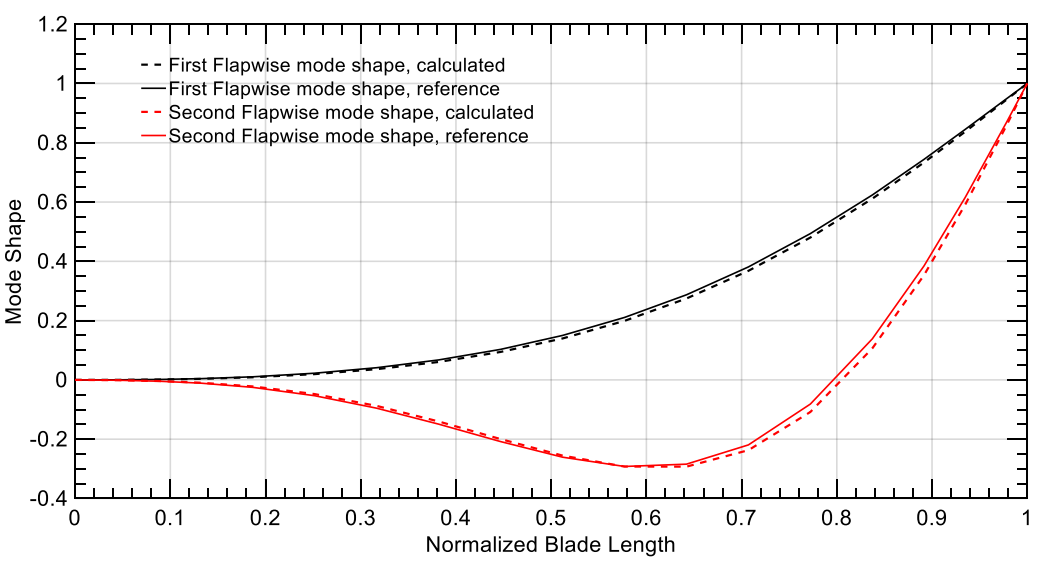

Figure 6. Blade flap-wise mode shapes.

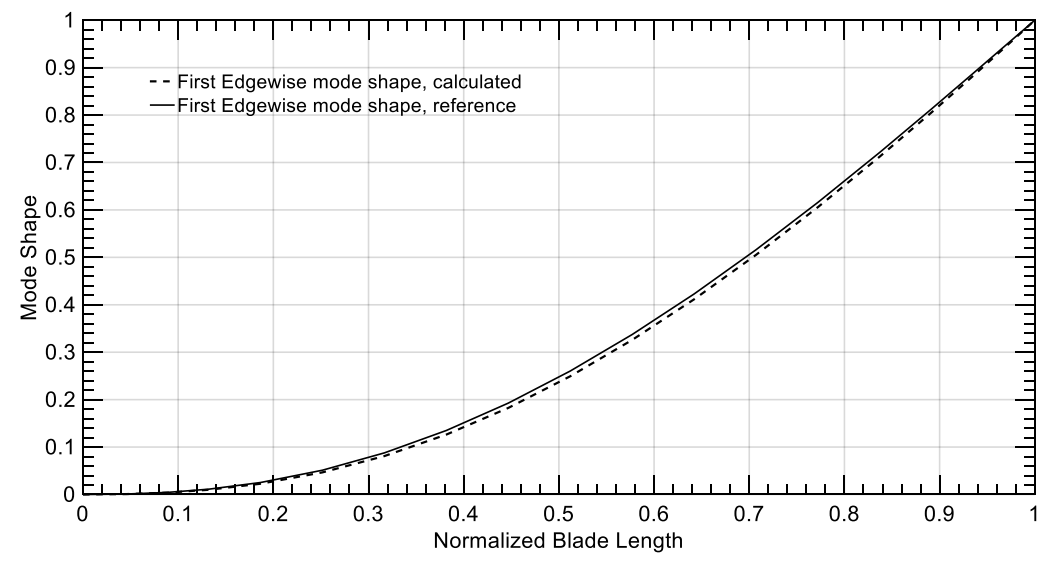

Figure 7. Blade edge-wise mode shape.

\subsubsection{Tower}

Similarly, the free vibrations of the tower are compared. The modes considered in the aeroelastic tool are the first and second fore-aft modes and the first side-side mode. Natural frequencies are shown in Table 2 and mode shapes are shown in Figures 8 and 9. 
Table 2. Natural frequencies for the tower: single rotor configuration.

\begin{tabular}{cccc}
\hline Mode & Calculated $\mathbf{( H z )}$ & Reference $\mathbf{( H z )}$ & Deviation $\mathbf{( \% )}$ \\
\hline First fore-aft & 0.32 & 0.32 & 0.0 \\
Second fore-aft & 3.06 & 2.90 & 5.2 \\
First side-side & 0.32 & 0.31 & 3.1 \\
\hline
\end{tabular}

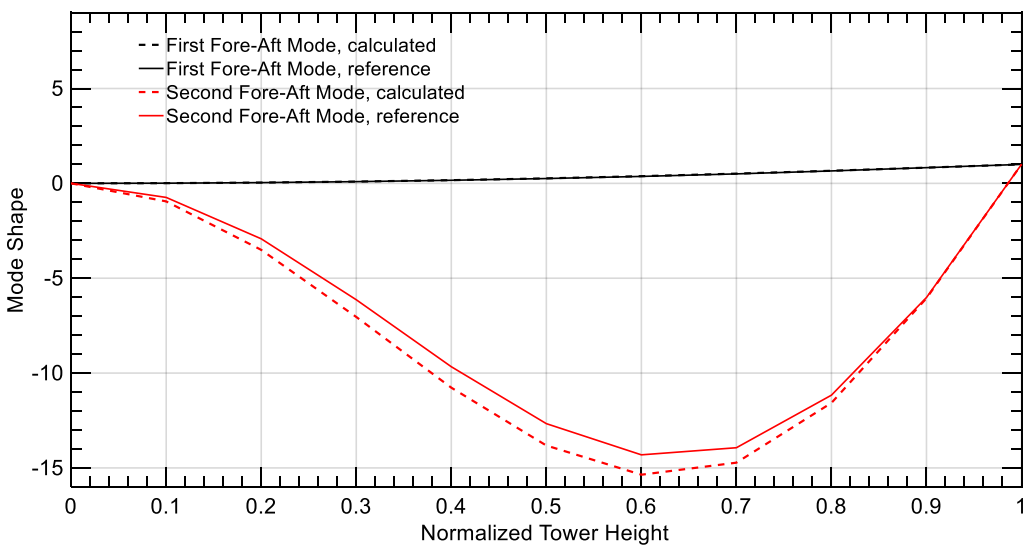

Figure 8. Tower fore-aft mode shapes: single rotor configuration.

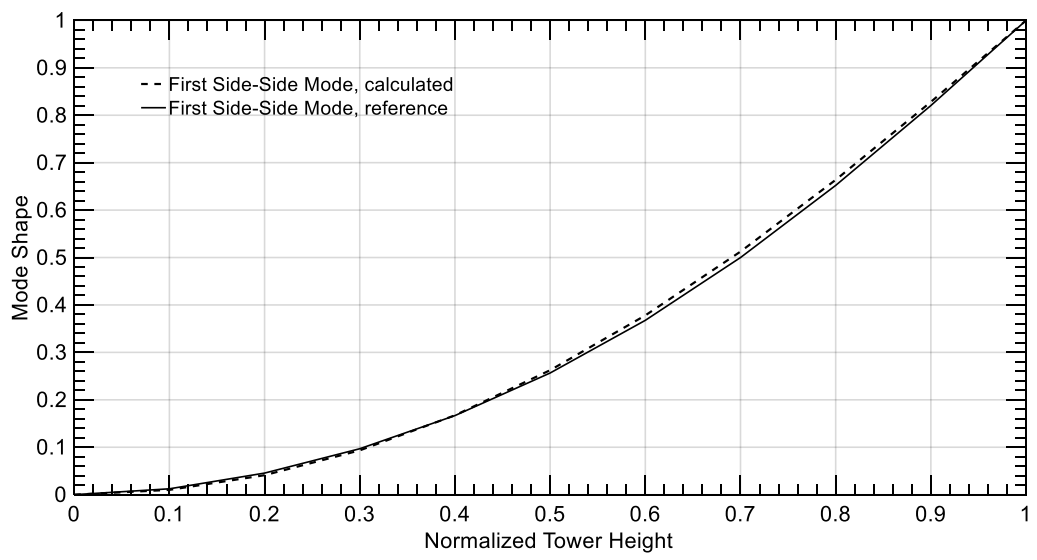

Figure 9. Tower side-side mode shape: single rotor configuration.

Natural frequencies as well as mode shapes of the tower show agreement between the results of Modes compared to the reference.

With the aerodynamic steady state response and the structure dynamic response verified separately, the next step is validation of the aeroelastic tool, where both aerodynamics and the structure of the turbine are coupled.

\subsection{Aeroelastic Analysis}

In this subsection, the coupling between the aerodynamic loads and the structural behavior is introduced. The aerodynamic loads affecting the blades cause deformation, and hence the relative velocities on the blade sections are changed. Inertial loads generated from the blade vibration also affect the structural behavior. The effects of blade vibrations are considered every time step in the simulation to catch the aeroelastic behavior for both the blades and the tower.

For validation of the results, a FAST simulation is made for the NREL 5MW wind turbine blades and tower, using the same simulation conditions as in the in-house tool. The blades are subject to a constant wind speed and are rotating at a constant angular speed. Simulation parameters are as follows: 
- Wind speed: $11.4 \mathrm{~m} / \mathrm{s}$ (Rated wind speed)

- Rotational velocity: $12.1 \mathrm{rpm}$

- Pitch angle: $0^{\circ}$

- Time step: $0.01 \mathrm{~s}$

- Simulation time: $50 \mathrm{~s}$

\subsubsection{Blades}

For the simulation of the blades, the tower is considered as a stiff body. The dynamics are generated from the rotation of the blades in the azimuth direction and the vibrations in the flap-wise and edge-wise directions. Further, the tower is considered to be a stiff body in the FAST simulation to create a similar simulation environment for comparison. In Figures 10 and 11, bending moments at the blade root in the flap-wise and edge-wise directions are shown with the azimuth position of the blade.

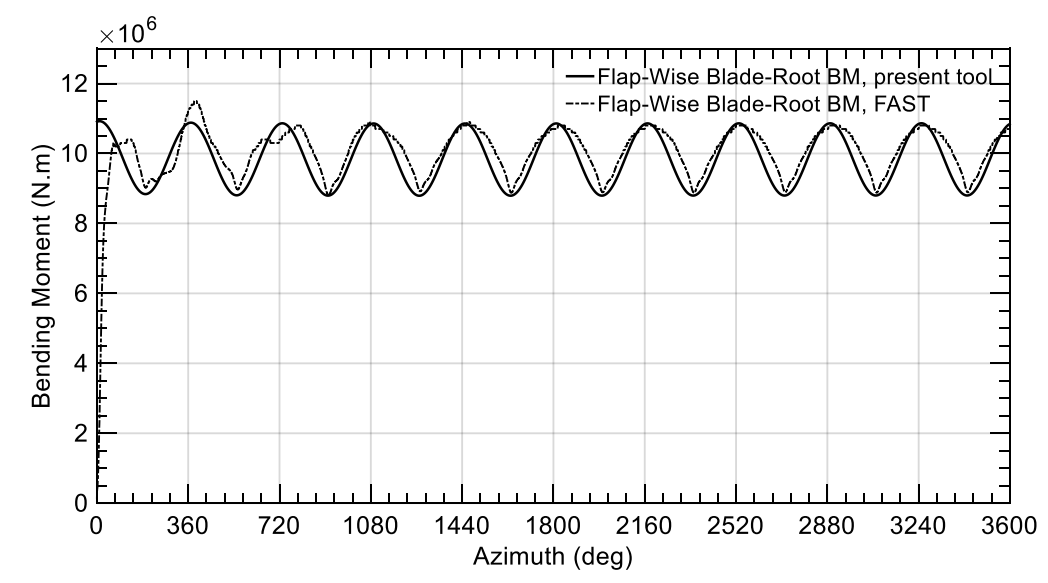

Figure 10. Blade-root, flap-wise bending moment.

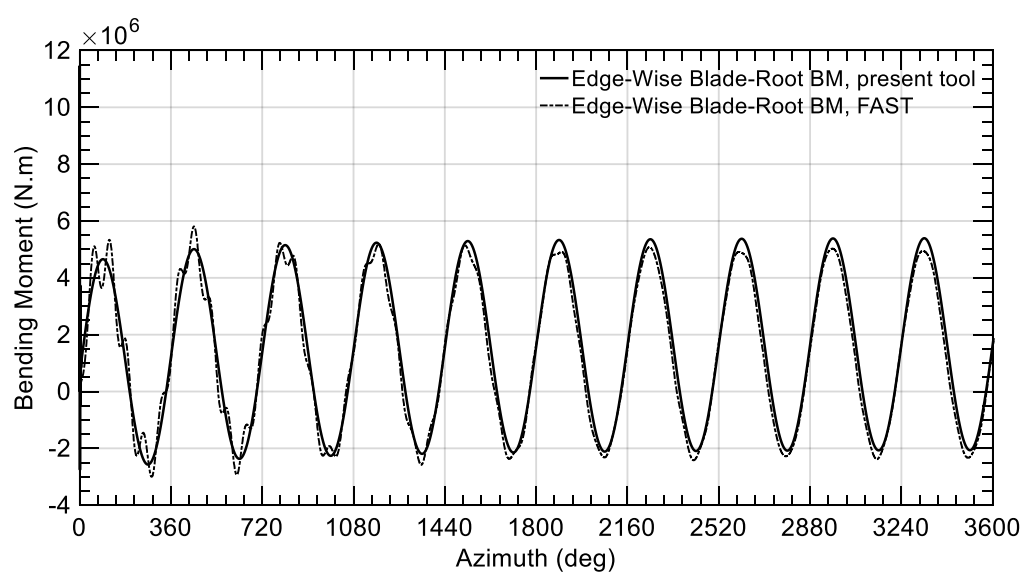

Figure 11. Blade-root, edge-wise bending moment.

The periodic behaviour of the dynamic response of the blade is due to the effect of gravity and inertia on the blades while in different azimuth positions, as well as the shear layer of the flow. As the blade rotates, considering the rotor's tilt angle, the mass centred along the blade length moves such that the blade moves towards or away from the plane of rotation.

Figures 12 and 13 show the blade tip deflections. 


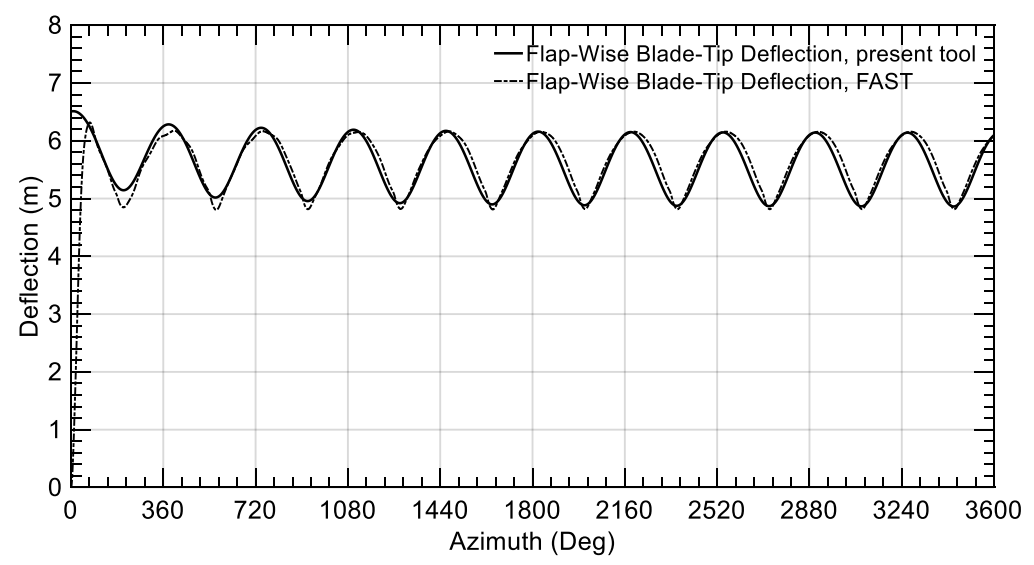

Figure 12. Blade-tip, flap-wise deflection.

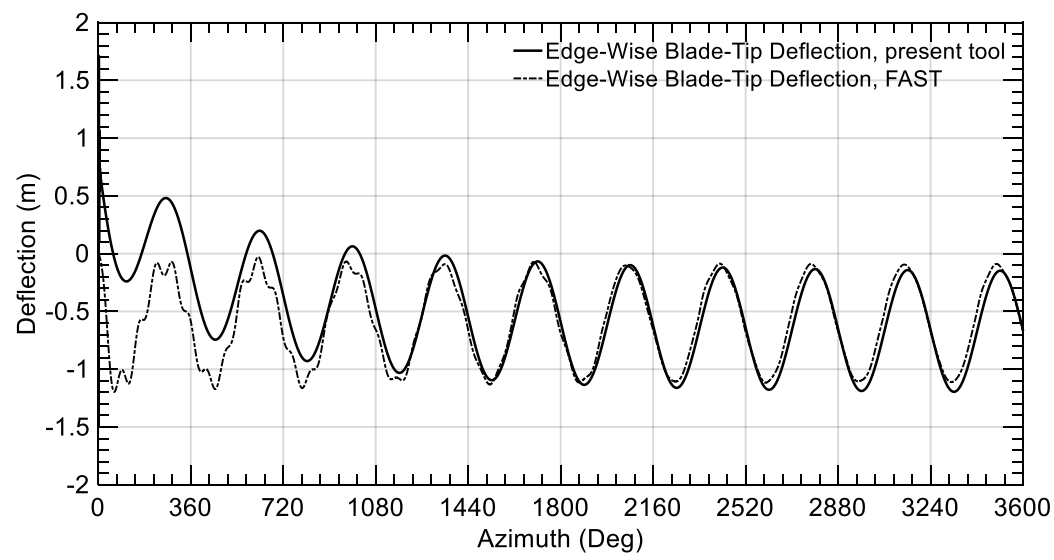

Figure 13. Blade-tip, edge-wise deflection.

There are some discrepancies between the results of the present tool and FAST, especially in the initial runs of the simulation. Those discrepancies are due the difference in the natural frequencies and mode shapes between the present tool and FAST. The aeroelastic model might as well be modeled in a different way in FAST than in the present tool. Other than the initial condition, there is a very good agreement between the results of the present tool and FAST results in terms of the ranges of values, mean values, and frequencies of each time series. Consequently, the proposed tool has proved its ability to describe the blade dynamics and hence its ability to model the tower.

\subsubsection{Tower}

The tower is now considered for study. The same conditions of simulation were set for both the proposed tool and FAST. The loads were transmitted from the rotor to the tower, considering the dynamic behavior of the rotor loads. The elasticity of the tower together with the aerodynamic and gravitational loads of the tower itself were also considered. As observed from the dynamic responses of the blade, the out-of-plane quantities are more significant than the in-plane ones, and hence, the out-of-plane properties for the tower are shown for comparison.

It is observed in Figures 14 and 15 that there is a very good agreement between the results of the present tool compared to FAST. Discrepancies appear in the tower dynamics in the initial runs as well. This is due to difference in the rotor loads, which appeared in the blade's results, as well as differences in the natural frequencies of the tower itself. 


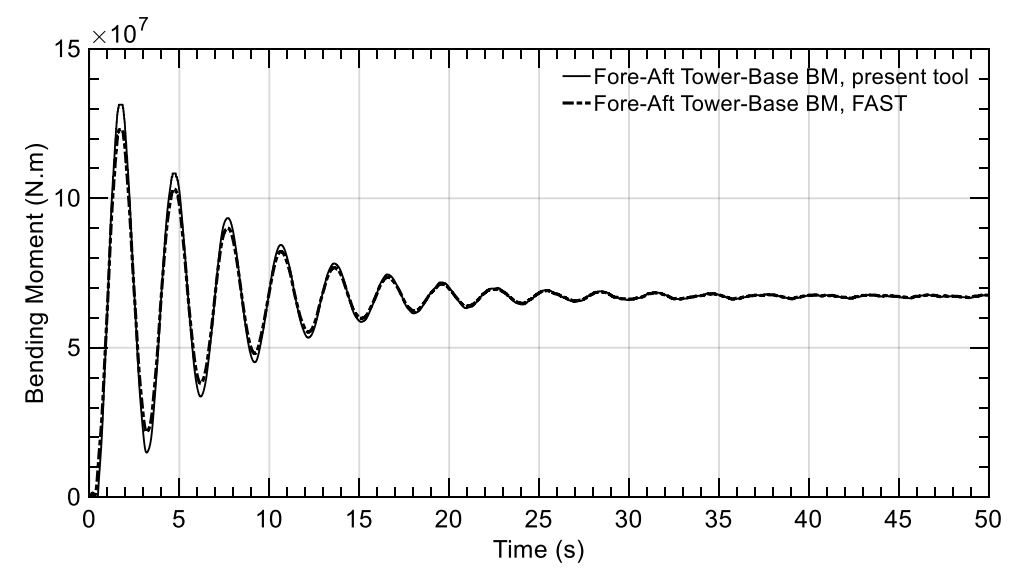

Figure 14. Tower-base, fore-aft bending moment.

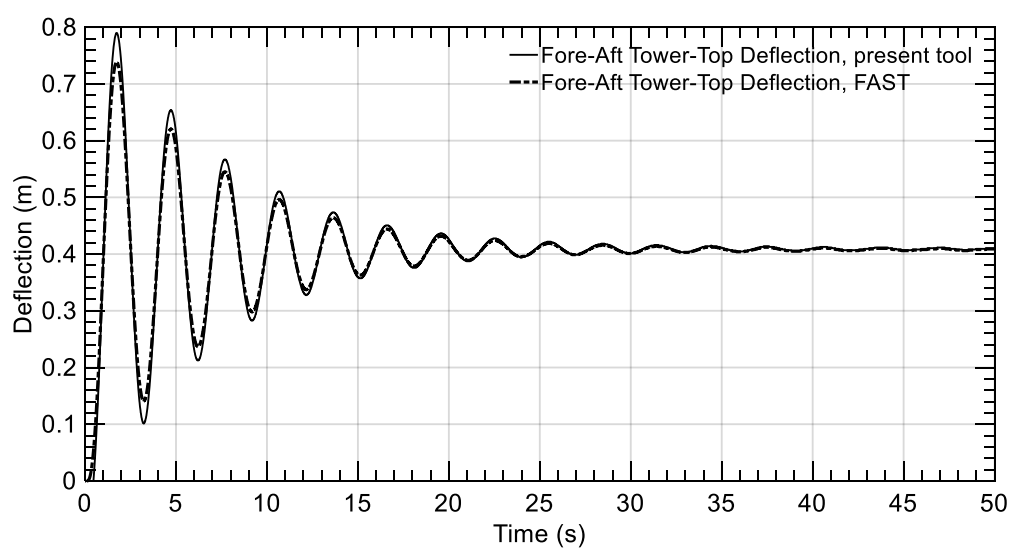

Figure 15. Tower-top, fore-aft deflection.

For both the blade and tower dynamic responses, the results of the proposed tool have shown credibility in modeling the aeroelastic behavior of a wind turbine. So far, the tool is able to generate loads and deflections' time series for the turbine parts in case of a steady wind. In the next section, another rotor is added on the same tower, and the tower dynamics are studied.

\section{Simulation of the Twin-Rotor Model}

\subsection{Twin-Rotor Wind Turbine Model}

In this section, the tower of a twin-rotor turbine with two NREL 5MW rotors is modeled. The support structure is assumed to be a T-shaped structure, with the main tower and two side booms connecting the rotors. The side booms are assumed to be a scaled-down structure of the NREL 5MW main tower, each of $63.5 \mathrm{~m}$ in length from the main tower center point, such that the two rotors are distanced at 127 meters from hub to hub. These booms' lengths were chosen such that the tips of each of the $126 \mathrm{~m}$ diameter rotors are $1 \mathrm{~m}$ apart.

It is also assumed that there is no aerodynamic interaction between the two rotors. This assumption can be only accepted as preliminary study, as in reality, rotors affect each other. However, to account for that assumption, a pitch misalignment of $0.2^{\circ}$ and $-0.2^{\circ}$ is added to each rotor's second and third blades, respectively, which is common to generate aerodynamic imbalance. Figure 16 shows a sketch of the proposed twin-rotor configuration.

For comparison of the tower's structural behavior between single and twin rotor configurations, the main tower's geometry and structural properties are changed such that the natural frequency of the first fore-aft mode is the same for both towers. The outer diameter of the tower is changed while the thickness is kept constant. It was found that an outer diameter 1.25 times the diameter of the 
single-rotor configuration turbine will cause the first fore-aft natural frequency of both configurations' towers to be equal. Table 3 shows the differences in the geometry between both configurations.

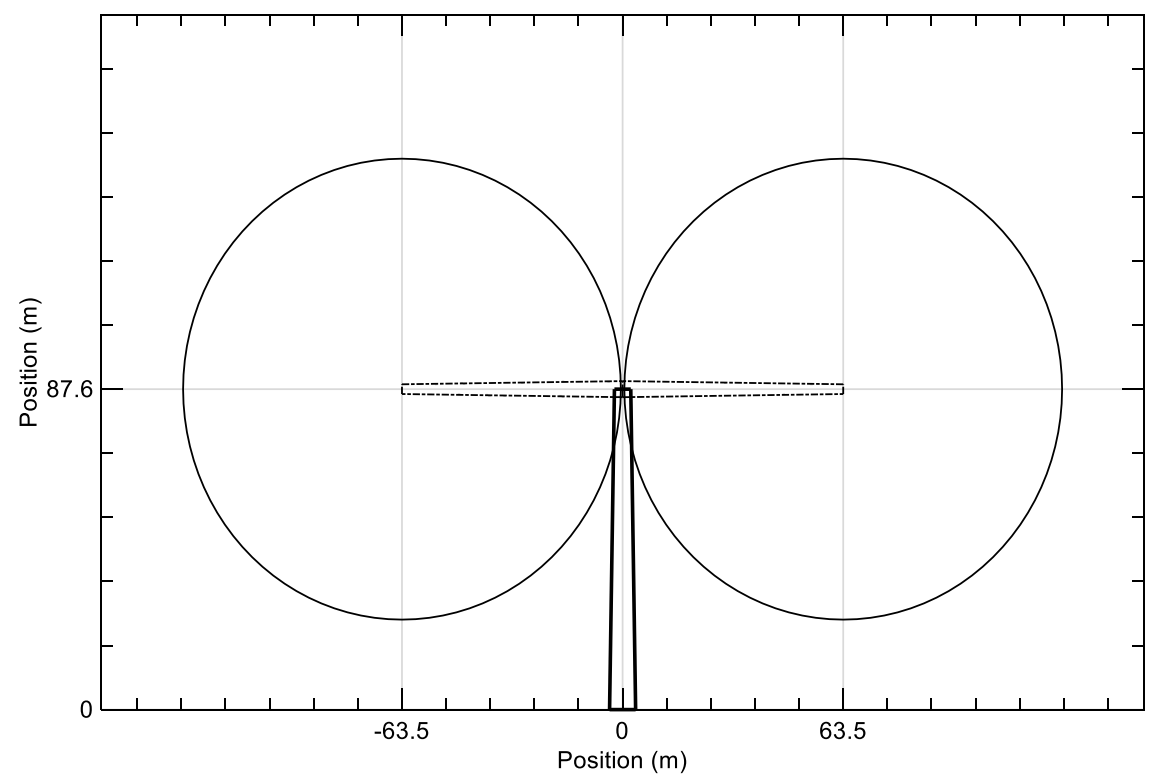

Figure 16. Sketch of the twin-rotor configuration.

Table 3. Tower geometry.

\begin{tabular}{ccc}
\hline Property $(\mathbf{m})$ & Single rotor & Twin rotor \\
\hline Tower base diameter & 6.000 & 7.500 \\
Tower base thickness & 0.027 & 0.027 \\
Tower top diameter & 3.870 & 4.840 \\
Tower top thickness & 0.019 & 0.019 \\
Tower height & 87.600 & 87.600 \\
\hline
\end{tabular}

Figure 17 shows the difference in the mass and stiffness distributions between the single rotor and twin rotor configurations' towers.

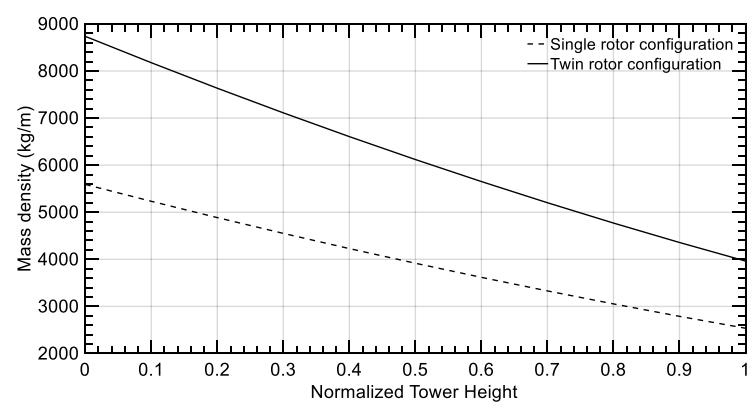

(a)

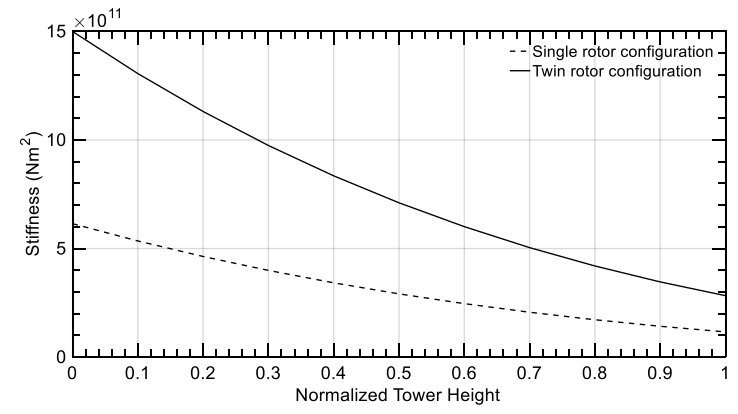

(b)

Figure 17. Tower structural properties: single rotor vs. twin rotor: (a) tower mass density distribution; (b) tower stiffness distribution.

The natural frequencies in case of the twin rotor configuration are shown in Table 4.

The natural frequencies other than the first fore-aft mode are changed compared to the single rotor configuration. This means that the tower stiffness and structural damping matrices in the mathematical model in the case of the twin rotor are different. Moreover, the loads are increased 
significantly due to the addition of another rotor, and hence the deformations are expected to change in a non-straightforward way.

Table 4. Natural frequencies for the tower - Single Vs. Twin rotor configuration.

\begin{tabular}{cccc}
\hline Mode & Single rotor $\mathbf{( H z )}$ & Twin rotor $\mathbf{( H z )}$ & Deviation $\mathbf{( \% )}$ \\
\hline First fore-aft & 0.32 & 0.32 & 0.0 \\
Second fore-aft & 3.06 & 3.20 & 4.4 \\
First side-side & 0.32 & 0.25 & 21.8 \\
\hline
\end{tabular}

\subsection{Simulation Conditions}

Two load cases were investigated for the twin rotor configuration; one is in a steady wind condition, and the other is in turbulent wind conditions.

In the steady wind case, the rotors are subject to the same conditions as in the case of single rotor: a steady wind velocity of $11.4 \mathrm{~m} / \mathrm{s}$, rotating the rotors at $12.1 \mathrm{rpm}$. This case studies the aeroelastic properties when the two rotors are rotating simultaneously, such that the rotor loads are superimposed in all the loads' value ranges, and then investigates when the rotors have a $60^{\circ}$ phase change in the blades' azimuth positions.

In the turbulent wind condition case, the rotors are subject to a turbulent wind field created by NREL's tool TurbSim [21]. The rotors are subject to different turbulence classes according to IEC 61400-1 standards [22] at an average wind speed at the hub height of $8 \mathrm{~m} / \mathrm{s}$ and turbulence intensities of class A (high turbulence), B (moderate turbulence), and C (low turbulence). A variable speed control algorithm is used in the turbulent case.

In all cases, the out-of-plane dynamic responses—deflection and bending moment—of the tower are shown.

\subsubsection{Case 1: Steady Flow Condition}

In this case, the two rotors' loads superimpose in the whole range of values, in the peak values at the beginning of rotation and until it settles for the nominal value of the load, while the blades of both rotors are in the same azimuth position.

First, the tower was modeled as a stiff tower, and the bending moment at the tower base is calculated. Then this model is compared to an elastic tower model to see the differences in results. The results of this simulation are shown in Figure 18.

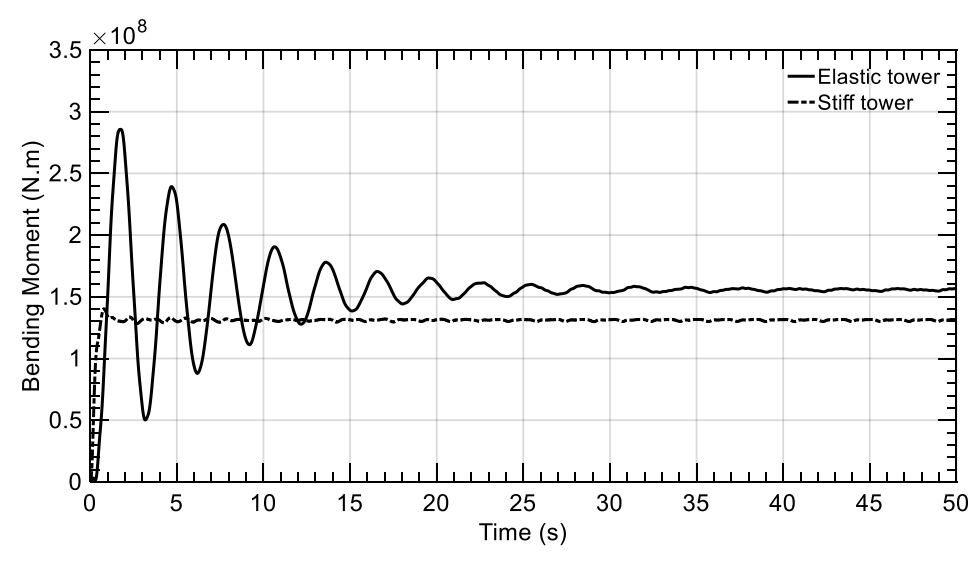

Figure 18. Tower-base fore-aft bending moment: stiff vs. elastic tower.

The stiff tower model doesn't show the dynamic behavior of the load; moreover, the values are less than those in the elastic tower model. The gravity effects due to the vibration of the tower are eliminated in the case of the stiff tower, and hence the loads are far from the real values. This proves 
that it is not proper to consider the tower to be a stiff for load calculations and it is important to model it as an elastic tower.

Dynamic responses for the elastic tower model were then calculated, Figures 19 and 20 show the tower-base bending moment and tower-top deflection in the fore-aft direction.

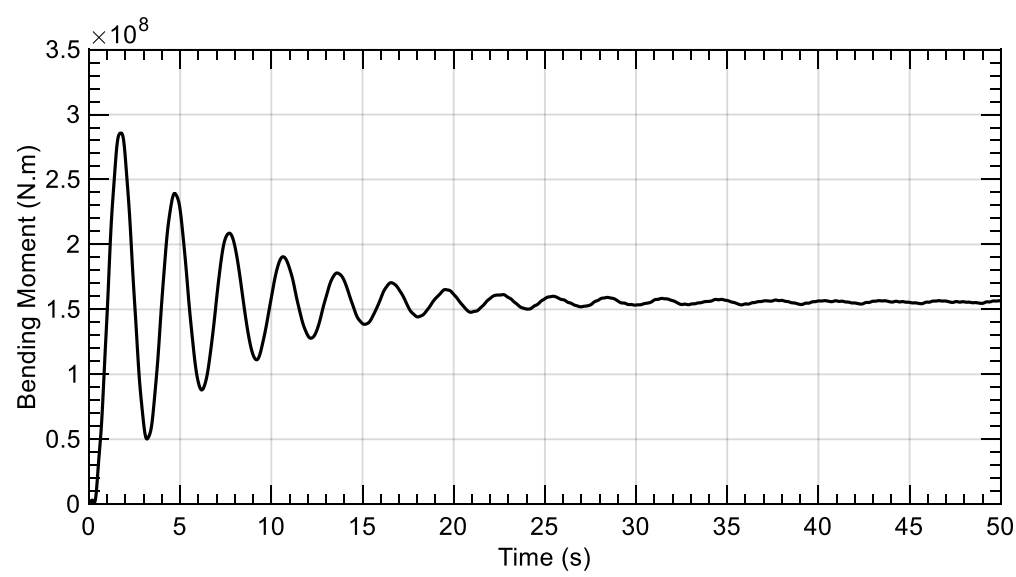

Figure 19. Tower-base, fore-aft bending moment.

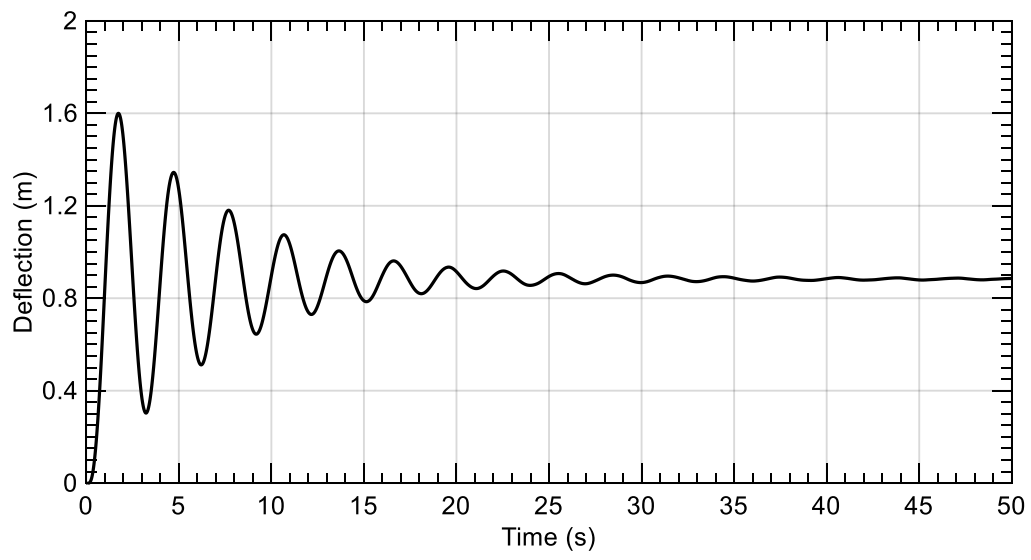

Figure 20. Tower-top, fore-aft deflection.

As was expected, the change in the values of deflection of the tower top and bending moment of the tower base is not linear with the addition of an extra rotor. The change is affected by both the added load and the change in the natural frequencies of the new tower's geometrical properties and hence the stiffness and damping matrices in the mathematical model. The difference is elaborated clearly in Figure 21, where the results of the single-rotor and twin-rotor are shown together.

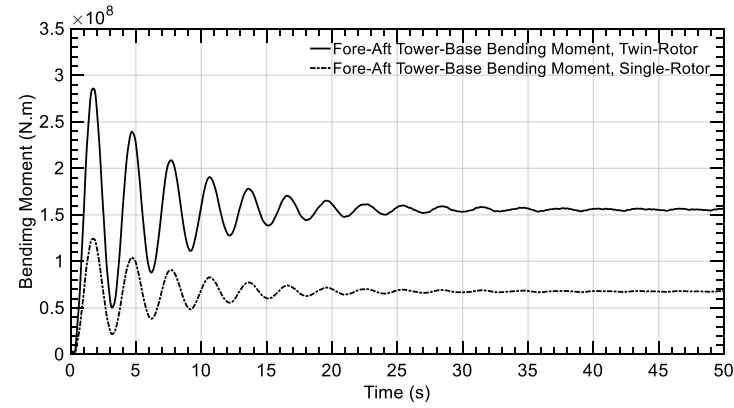

(a)

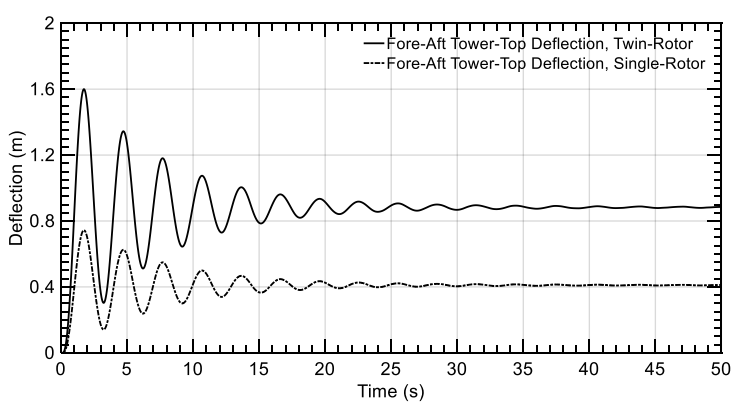

(b)

Figure 21. Dynamic responses of the tower: single-rotor vs. twin-rotor load case 1: (a) tower-base, fore-aft bending moment, and (b) tower-top, fore-aft deflection. 
For a tower with the same first fore-aft natural frequency as the single-rotor configuration, the effect of adding one more rotor on the dynamic responses is not straightforward. Two simultaneously rotating rotors on the same tower increase the tower loads and deflections are more than doubled. This is due to the change in the structure of the mathematical model and the added weight and rotor inertias on the top of the tower, which change the natural frequencies in the second fore-aft and first side-side directions.

Then, a phase difference in the initial azimuth position of the first blade of each rotor of $60^{\circ}$ is investigated for comparison. The dynamic responses of the tower are shown in Figures 22 and 23.

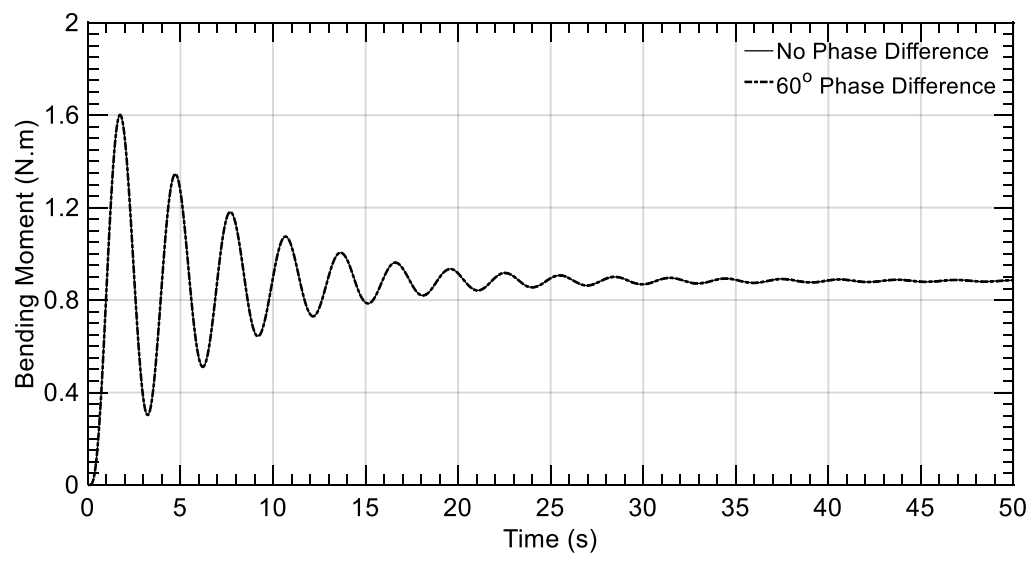

Figure 22. Tower-base, fore-aft bending moment.

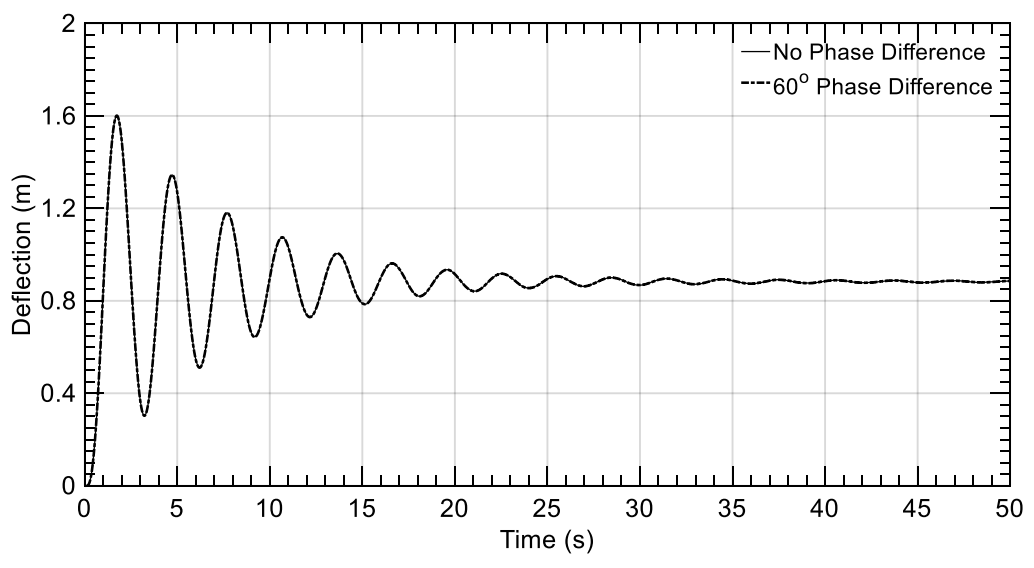

Figure 23. Tower-top, fore-aft deflection.

Here, the dynamic responses of the tower are almost identical with the no phase difference case, but there is a very slight difference which can only be seen only by zooming into the graph. However, with the phase change between the azimuth position of the rotors' blades, there is a slight phase change in the rotor loads, and hence a twisting moment is generated on the tower causing a yawing deflection, which should be studied to anticipate its effect. The yawing deflection of the tower-top is shown in Figure 24.

When the two rotors were rotating simultaneously and under the same aerodynamic conditions, there was no twisting moment for the tower and hence no deflection. When only a phase change between the rotors occurred, a twisting moment was generated causing angular deflection. For different wind conditions the effect of twist can be severe and cause torsional fatigue and hence failure. So, for a twin-rotor configuration, torsional stiffness should be carefully considered in the tower design. 


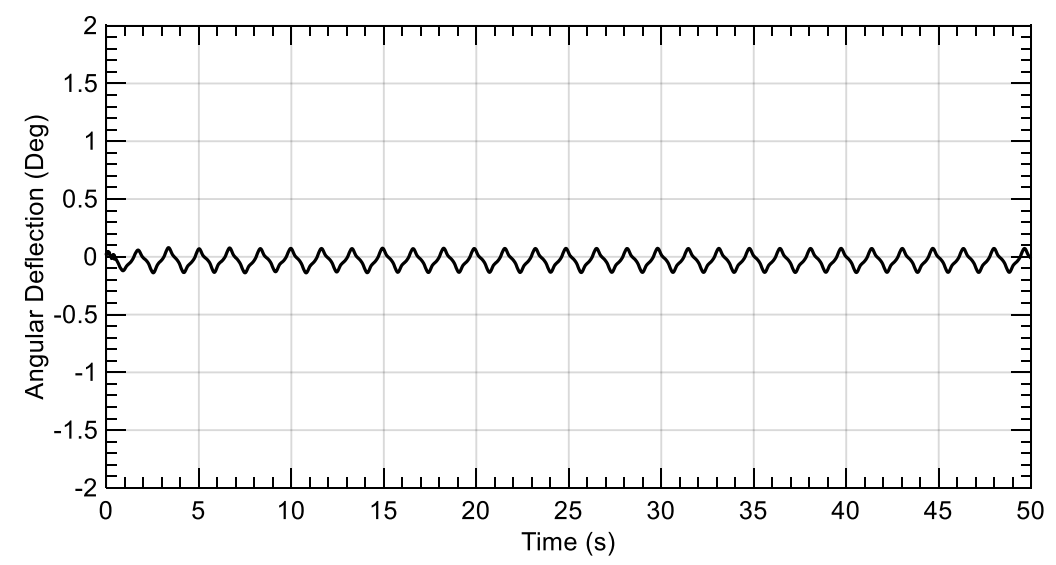

Figure 24. Tower top yawing deflection - Load case 2.

\subsubsection{Case 2: Turbulent Flow Condition}

In this case, the rotors are subject to a turbulent flow field, using the IEC Kaimal spectral model. Fields having turbulence intensities of IEC 61400 classes A, B, and C, with an average wind speed of $8 \mathrm{~m} / \mathrm{s}$, were created with TurbSim. The turbulent grid width was doubled to be able to cover both rotors. Variable speed control was applied to control the rotating speed of the rotors. The generator specifications are available in the NREL 5MW definition report [14]. For a gear ratio of 97:1 and a generator efficiency of $94.4 \%$, the optimal constant of proportionality will be $0.0255764 \mathrm{~N} . \mathrm{m} / \mathrm{rpm}{ }^{2}$. The simulation was run for 10 minutes, and the tower dynamic responses were calculated. Figure 25 shows the wind speed at the hub height for all the turbulent cases. Figure 26 shows the tower-base for-aft bending moment and the tower-top fore-aft deflection time series.

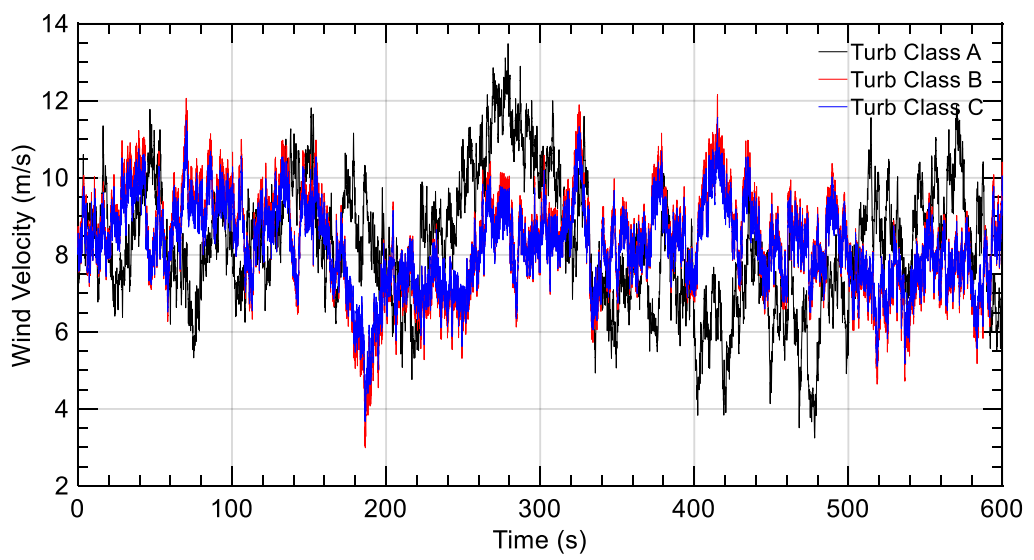

Figure 25. Wind Speed at Hub Height.

Since the turbulent domain covers both rotors, it is expected that each rotor experiences different wind conditions, which indicates the presence of torsional moment over the tower. The yawing deflection over the tower is shown for each turbulence case in Figures 27-29.

It is clear that the turbulent nature of the flow has affected the behavior of the yawing deflection. The deflection is quite random and does not have a general trend, unlike the case of steady wind where the deflection had a periodic nature. This randomness indicates unfavored instability in the dynamics, which affect the lifetime of the turbine, and a thorough fatigue study must be made to avoid sudden failures. 


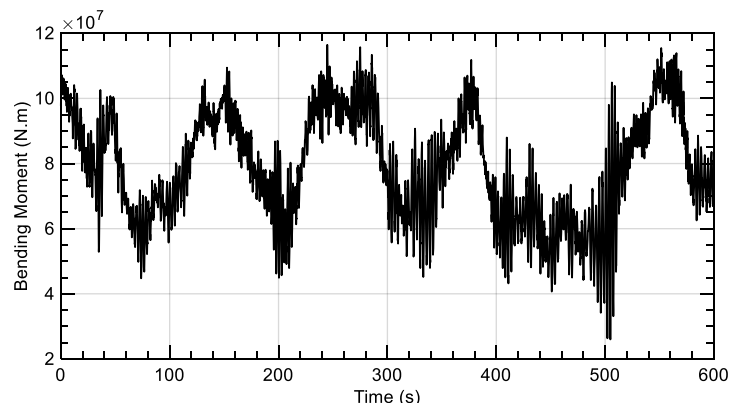

(a)

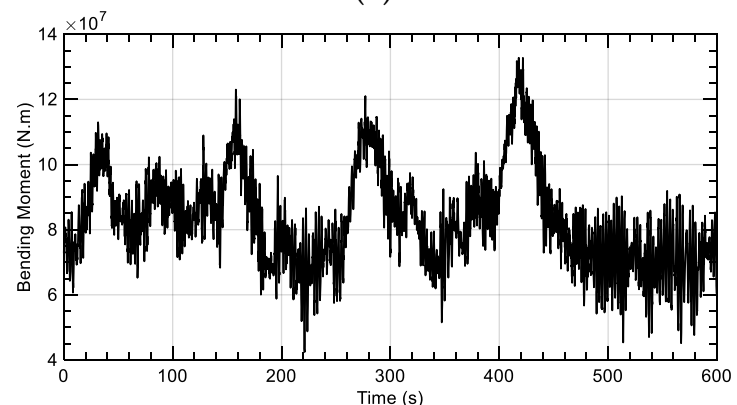

(c)

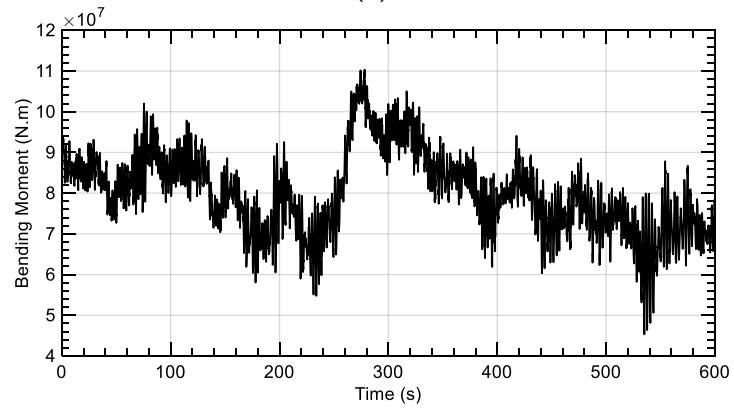

(e)

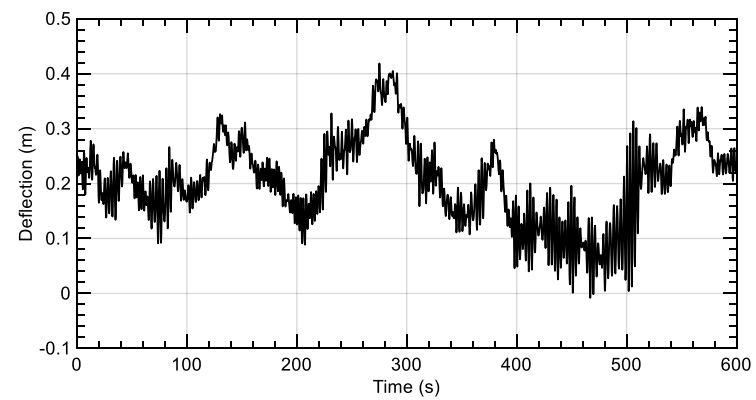

(b)

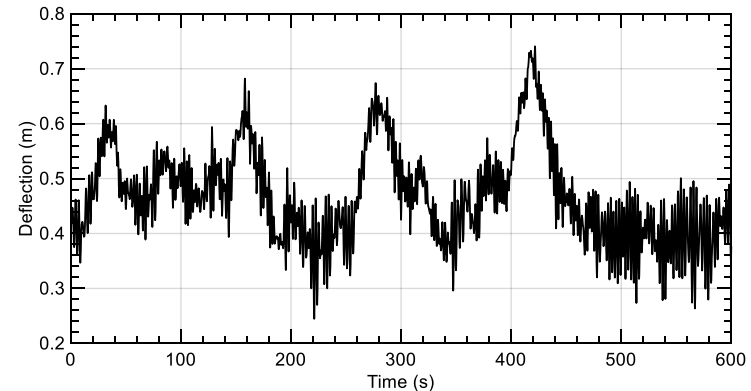

(d)

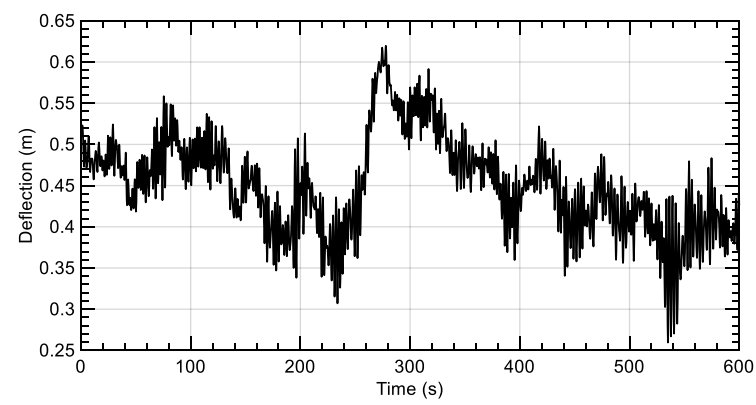

(f)

Figure 26. Tower Dynamic Responses; (a) Tower-Base Fore-aft Bending Moment, Turb. Class A; (b) Tower-Top Fore-aft Deflection, Turb. Class A; (c) Tower-Base Fore-aft Bending Moment, Turb. Class B; (d) Tower-Top Fore-aft Deflection, Turb. Class B; (e) Tower-Base Fore-aft Bending Moment, Turb. Class C; and (f) Tower-Top Fore-aft Deflection, Turb. Class C.

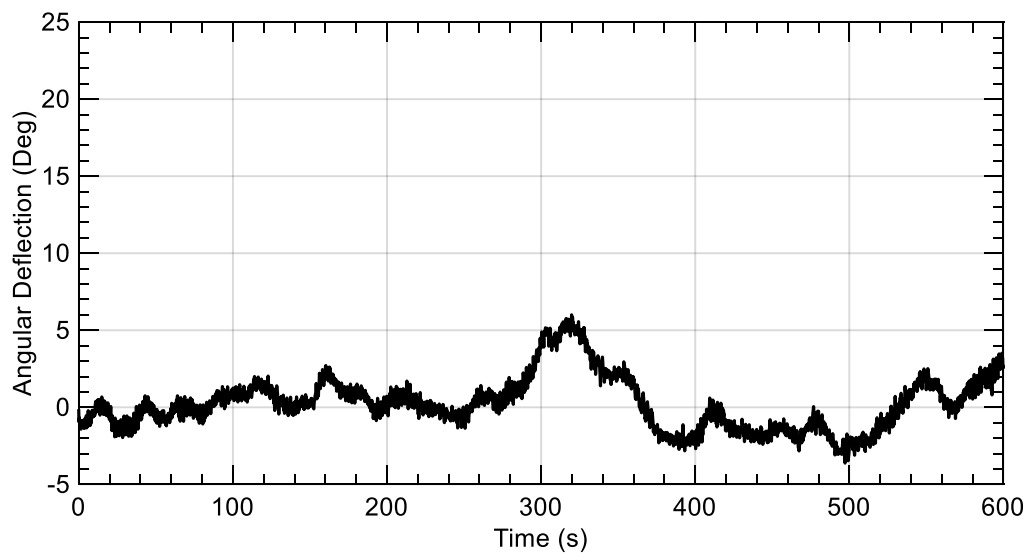

Figure 27. Tower top yawing deflection: turb. class A. 


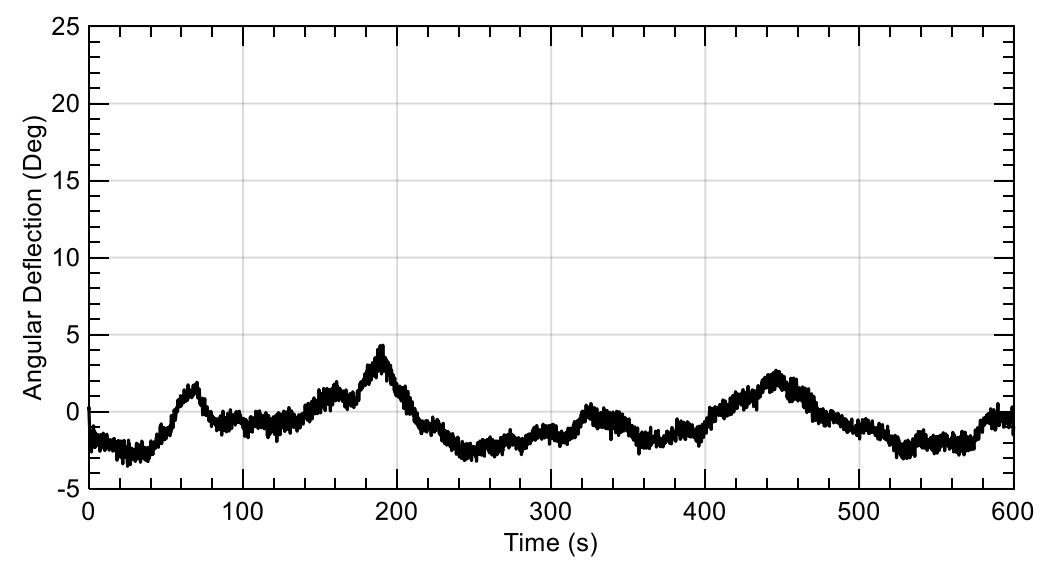

Figure 28. Tower top yawing deflection: turb. class B.

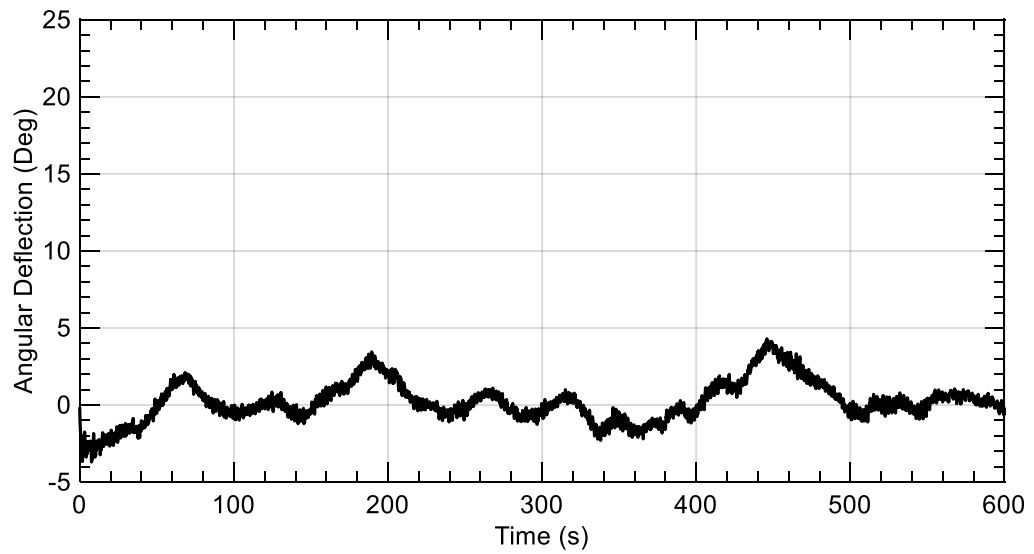

Figure 29. Tower top yawing deflection: turb. class $\mathrm{C}$.

Frequency analysis has been made for the bending moment dynamic response of the tower. Figures $30-32$ show the results.

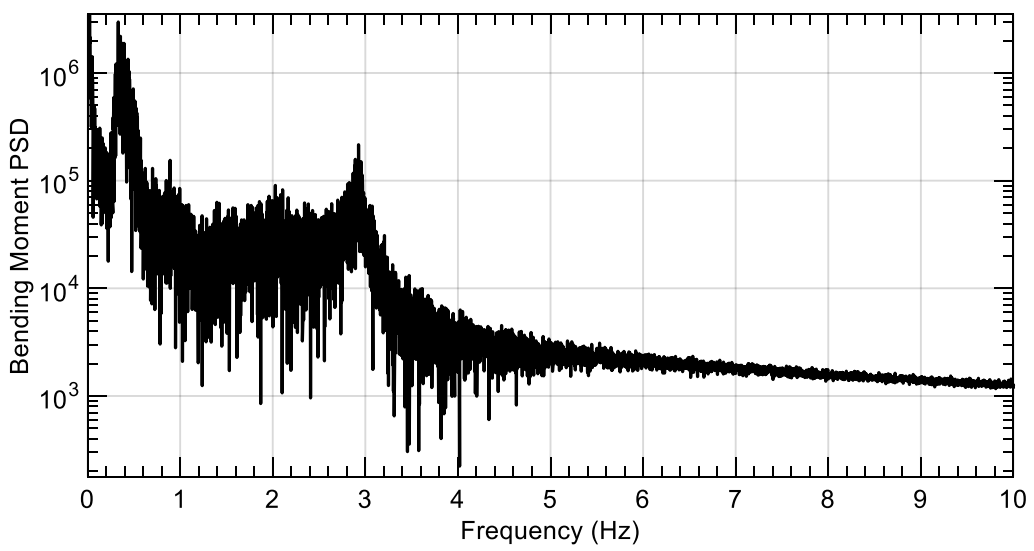

Figure 30. Frequency analysis, tower-base bending moment, turb. class A.

Frequency analyses in all turbulent cases shows that the dominant frequencies are at $0.32 \mathrm{~Hz}$ and $3 \mathrm{~Hz}$, which are the same as the free vibration natural frequencies of the tower.

Comparison between dynamic response of the tower-base bending moment for the turbulent flow load cases is shown in Table 5 . 


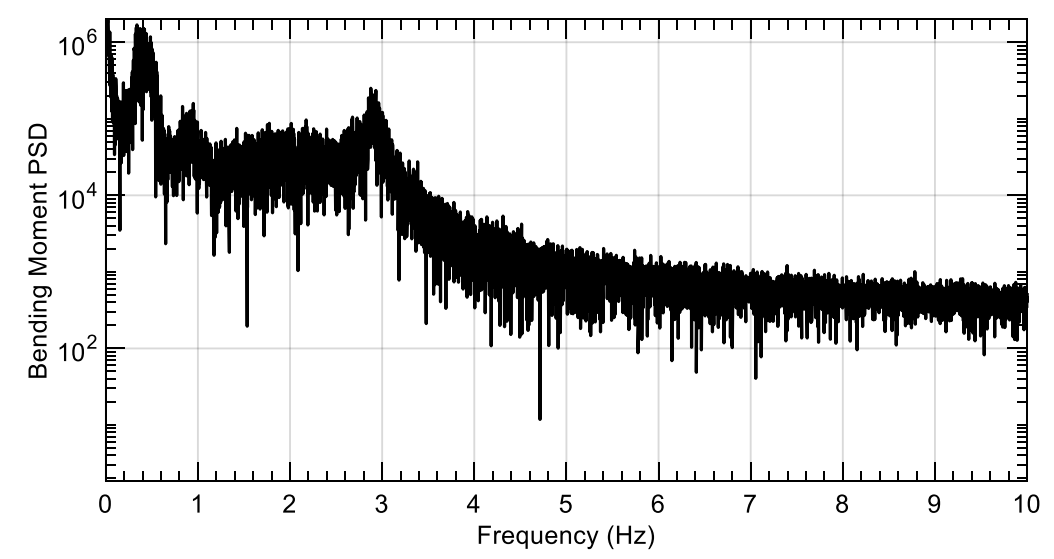

Figure 31. Frequency analysis, tower-base bending moment, turb. class B.

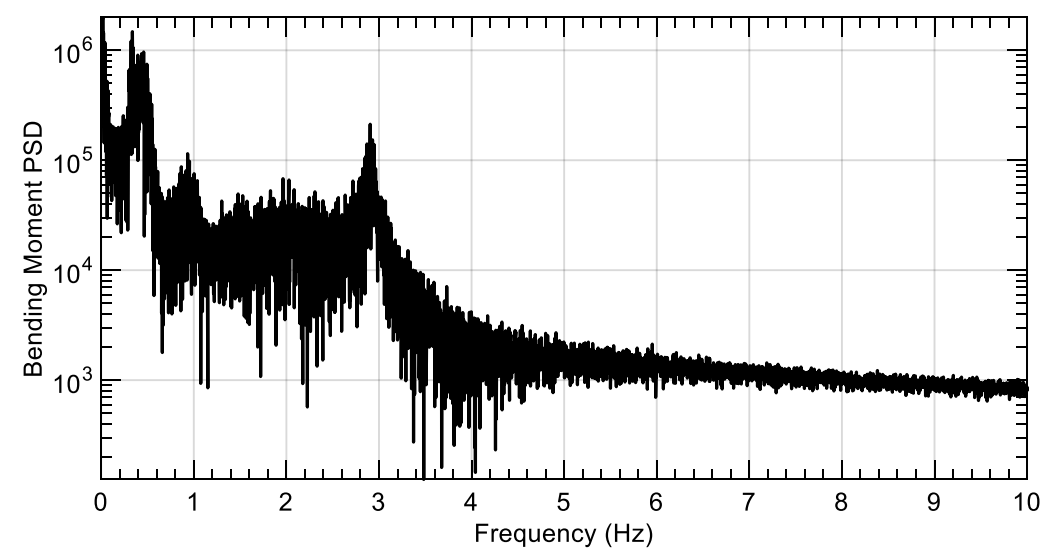

Figure 32. Frequency analysis, tower-base bending moment, turb. class $\mathrm{C}$.

Table 5. Statistical analysis for tower-base bending moment in turbulent cases.

\begin{tabular}{cccc}
\hline Turbulence Class & Mean Value & Standard Deviation & Dominant Frequencies \\
\hline A & $8.00 \times 10^{7}$ & $1.79 \times 10^{7}$ & $0.32 \mathrm{~Hz}$ and $3 \mathrm{~Hz}$ \\
B & $8.25 \times 10^{7}$ & $1.53 \times 10^{7}$ & $0.32 \mathrm{~Hz}$ and $3 \mathrm{~Hz}$ \\
C & $8.06 \times 10^{7}$ & $1.14 \times 10^{7}$ & $0.32 \mathrm{~Hz}$ and $3 \mathrm{~Hz}$ \\
\hline
\end{tabular}

Statistical analysis in Table 5 has shown that the tower's natural frequencies are dominant over the flow condition. For the high turbulence intensity, the mean value of the load is less than the other intensities; however a higher standard deviation occurs, which indicates severe oscillation of the loads.

\section{Conclusions}

In this work, an aeroelastic tool has been developed to provide a two-way FSI model for wind turbine blades and a tower. The tool is validated for a single-rotor configuration and gave very reasonable results. It has been extended to model the aeroelastic behavior of a twin-rotor configuration. Dynamic response of the support tower was investigated for two load cases. The outcomes of this work can be summarized as follows:

- The developed tool has been sufficiently validated for a single-rotor configuration when compared to results of FAST analysis. It can be trusted to model a twin-rotor configuration.

- Tower elasticity should be considered when studying the tower dynamics. The stiff tower model does not count for the vibration and hence the inertial loads of the tower, causing misleading results of the loads in terms of value and behavior. 
- For a tower with the same first fore-aft natural frequency, if one more rotor is added; it does not only increase the loads, but also changes the natural frequencies of the rotor and hence the stiffness and structural damping. Accordingly, the change in the tower deflections and loads is not straightforward with the number of rotors.

- Tower torsion is very crucial in case of twin-rotor configuration. The normal case is that the two rotors are not rotating simultaneously, and the results of this work have shown yawing deflections of the tower in case there is a slight phase change in the rotor loads' time series.

- Tower natural frequencies are dominant over the flow conditions for the tower loads and deflections.

The next step to improve the present tool is to implement pitch control, so that high power regions can be modeled. Also, eliminate the assumption of no aerodynamic interaction between the rotors, to study its effect on the dynamics and the optimum distance between the rotors to improve performance.

Author Contributions: A.I. did most of the work for modelling, programming, analyses, discussion, and writing of the manuscript. S.Y. contributed by supervising the work, mentoring, technical advising, and revising the work.

Funding: This work was conducted with the support of Japanese Ministry of Education, Culture, Sports, Science and Technology (MEXT).

Acknowledgments: Special thanks to Professor Martin O. L. Hansen, and Professor Taeseong Kim who helped a lot in understanding the fundamental information for wind turbine aeroelasticity.

Conflicts of Interest: The authors declare no conflict of interest.

\section{Abbreviations}

$\begin{array}{ll}\text { BEM } & \text { Blade Element Momentum } \\ \text { CAD } & \text { Computer Aided Drawing } \\ \text { CFD } & \text { Computational Fluid Dynamics } \\ \text { FAST } & \text { Fatigue, Aerodynamics, Structure, Turbulence } \\ \text { IEC } & \text { International Electrotechnical Commission } \\ \text { MRS } & \text { Multi Rotor System } \\ \text { NREL } & \text { National Renewable Energy Laboratory }\end{array}$

\section{References}

1. Global Wind Energy Council (GWEC). Global Wind Report; Global Wind Energy Council: Brussels, Belgium, 2018.

2. GE Renewable Energy. Available online: https://www.ge.com/renewableenergy/wind-energy/turbines/ haliade-x-offshore-turbine (accessed on 25 January 2019).

3. Hofmann, M.; Sperstad, I.B. Will $10 \mathrm{MW}$ wind turbines bring down the operation and maintenance cost of offshore wind farms? Energy Procedia 2014, 53, 231-238. [CrossRef]

4. Jamieson, P. Multi Rotor Systems. In Innovation in Wind Turbine Design; Wiley-Blackwell: Chichester, UK, 2011.

5. Goltenbott, U.; Ohya, U.; Yoshida, S.; Jamieson, P. Aerodynamic interaction of diffuser augmented wind turbines in multi-rotor systems. Renew. Energy 2017, 112, 25-34. [CrossRef]

6. Chasapogiannis, P.; Prospathopoulos, J.M.; Voutsinas, S.G.; Chaviaropoulos, T.K. Analysis of the aerodynamic performance of the multi-rotor concept. J. Phys. Conf. Ser. 2014, 524, 012084. [CrossRef]

7. Yoshida, S.; Goltenbott, U.; Ohya, Y.; Jamieson, P. Coherence Effects on the Power and Tower Loads of a $7 \times 2$ MW Multi-Rotor Wind Turbine System. Energies 2016, 9, 742. [CrossRef]

8. Ghaisas, N.S.; Ghate, A.S.; Lele, S.K. Large-eddy simulation study of multi-rotor wind turbines. J. Phys. Conf. Ser. 2018, 1037, 072021. [CrossRef]

9. Van der Laan, M.P.; Andersen, S.J.; García, N.R.; Angelou, N.; Pirrung, G.R.; Ott, S.; Sjöholm, M.; Sørensen, K.H.; Neto, J.X.V.; Kelly, M.; et al. Power curve and wake analyses of the Vestas multi-rotor demonstrator. Wind Energy Sci. 2019, 44. [CrossRef] 
10. Verma, P. Multi Rotor Wind Turbine Design and Cost Scaling. Master's Thesis, University of Massachusetts Amherst, Amherst, MA, USA, September 2013.

11. Mate, G.M. Development of a Support Structure for Multi-Rotor Wind Turbines. Master's Thesis, University of Massachusetts Amherst, Amherst, MA, USA, September 2014.

12. Bazilevs, Y.; Yan, J.; Deng, X.; Korobenko, A. Computer Modeling of Wind Turbines: 2. Free-Surface FSI and Fatigue-Damage. In Archives of Computational Methods in Engineering; Springer: Dordrecht, The Netherlands, 2018.

13. Halawa, A.; Sessarego, M.; Shen, W.Z.; Yoshida, S. Numerical Fluid-Structure Interaction Study on the NREL 5MW HAWT. J. Phys. Conf. Ser. 2018, 1037, 022026. [CrossRef]

14. Jonkman, J. The New Modularization Framework for the FAST Wind Turbine CAE Tool. In Proceedings of the 51st AIAA Aerospace Sciences Meeting, Grapevine, TX, USA, 7-10 January 2013.

15. Vorpahl, F.; Popko, W. Description of the Load Cases and Output Sensors to be Simulated in the OC4 Project under IEA Wind Annex 30; Fraunhofer Institute for Wind Energy and Energy System Technology IWES: Bremerhaven, Germany, 2016.

16. Hansen, M.O.L. Unsteady BEM Model. In Aerodynamics of Wind Turbines, 2nd ed.; Earthscan: London, UK, 2008; pp. 85-102.

17. Hansen, M.O.L. Dynamic Structural Model of a Wind Turbine. In Aerodynamics of Wind Turbines, 2nd ed.; Earthscan: London, UK, 2008; pp. 125-138.

18. Jonkman, J.; Butterfield, S.; Musial, W.; Scott, G. Definition of a 5-MW Reference Wind Turbine for Offshore System Development; NREL Technical Report TP-500-38060; National Renewable Energy Lab: Golden, CO, USA, 2009.

19. Bazilevs, Y.; Hsu, M.C.; Akkerman, I.; Wright, S.; Takizawa, K.; Henicke, B.; Spielman, T.; Tezduyar, T.E. 3D Simulation of Wind Turbine Rotors at Full Scale. Part I: Geometry Modeling and Aerodynamics. Int. J. Numer. Methods Fluids 2011, 65, 207-235. [CrossRef]

20. NWTC Information Portal (Modes). Available online: https://nwtc.nrel.gov/Modes (accessed on 15 May 2019).

21. Jonkman, B.J.; Kilcher, L. TurbSim's User Guide: Version 1.06.00; Technical Report; National Renewable Energy Lab (NREL): Golden, CO, USA, 2012.

22. IEC. Wind Turbines-Part 1: Design RequirementsIEC-61400-1, 3rd ed.; International Electrotechnical Commission: Geneva, Switzerland, 2005. 